\title{
Phoenix - A Mine Environment Data Visualisation and Management System
}

\author{
A. Pudmenzky Centre for Mined Land Rehabilitation, The University of Queensland, Australia \\ L. Rossato Centre for Mined Land Rehabilitation, The University of Queensland, Australia \\ G. McIlveen Centre for Mined Land Rehabilitation, The University of Queensland, Australia \\ D.R. Mulligan Centre for Mined Land Rehabilitation, The University of Queensland, Australia
}

\section{INTRODUCTION}

Many thousands of dollars are spent by mining companies on gathering and analysing monitoring data from mine on-site instrumentation (measuring surface water and groundwater parameters, dust and noise, constructed cover performance, meteorological conditions, etc), establishing transects or similar for following changes in soil or other substrates, flora and fauna, and many other ad hoc specific purpose sampling locations. The resulting documentation is available in many different formats, including site and monitoring reports, photos, videos and audio recordings and may be scattered over several geographical locations. Surprisingly, very little attention is given to make this complete collection of knowledge available when and where it is needed - to the decision makers who are responsible for planning sustainable rehabilitation strategies for mine closure and lease relinquishment. To enable researchers, industry and regulating bodies alike to develop a holistic view from these large volumes of diverse historic and current data and therefore to make informed decisions, a Windows PC based software application named Phoenix was specifically developed by the Centre for Mined Land Rehabilitation (CMLR) at The University of Queensland.

\section{METHODOLOGY}

\subsection{Data Set}

Data from the Mt Leyshon gold mine in North Queensland, Australia, for which CMLR has been given data custodianship by Newmont Australia Ltd., has been used to demonstrate the advantages of using Phoenix in the closure process. The dataset contains readings from hundreds of monitoring locations measuring environmental parameters (weather conditions, surface and underground water, soil, sediment and vegetation changes), associated documentation in various formats, site photos and videos over approximately more than two decades, and will be updated until lease relinquishment.

\subsection{Hardware and Software}

Phoenix was designed and developed out of the need to manage the large datasets CMLR was trusted with in support of site closure management and to fulfil the Centre's need for a central mine rehabilitation data administration and investigation system. It is therefore an application tailor-made for this specific task, not a system forced into performing a task it wasn't designed for.

Phoenix was written as a compiled Matlab ${ }^{\circledR}$ application with an intuitive Graphical User Interface (GUI) and is distributed by CMLR as a self-installing package. The decision to develop Phoenix using Matlab ${ }^{\circ}$ as a high level programming language stemmed from the superior capabilities of Matlab ${ }^{\circledR}$ as a high-performance language for technical computing, visualization, programming and analysis with a solid history of acceptance for many technical applications, and the ability to rapidly prototype any desired feature. Phoenix is continually enhanced with new features requested by the users of the system.

The minimum recommended system configuration for Phoenix is a Pentium 4 with $1024 \mathrm{Mb}$ memory, Windows ${ }^{\circledR}$ XP SP2, graphics card with OpenGL ${ }^{\circledR}$ hardware acceleration, $80 \mathrm{~Gb}$ hard disk capacity, Internet 
Explorer $^{\circledR}$ V6 and Windows Media Player. A HP Compaq ${ }^{\circledR}$ nw8240 Mobile Workstation (contains ATI mobility FireGL ${ }^{\mathrm{TM}}$ V5000 graphics card) and a HP workstation xw6200 (with a ATI FireGL ${ }^{\mathrm{TM}}$ V3100 graphics card) work satisfactorily. More information on Phoenix is available from Pudmenzky (2006).

\subsection{Data Capture}

The data capture process consisted of three basic steps, i) capture of the aerial photo of the mine operation and the digital terrain model (DTM) derived from it, ii) capture of individual sampling locations, and iii) the actual data captured at sampling locations. The following sections describe those steps in detail.

\subsubsection{Terrain and aerial photo}

The DTM data was derived from aerial photos taken with a stereo camera at high altitude. This process was performed by spatial information consultants such as AAMHatch as was the case for the Mt Leyshon gold mine. The 3-dimensional surface coordinates were collected in a text file and read into Phoenix (Figure 1a). This process took about one second for the $10 \mathrm{Mb}$ file describing Mt Leyshon.

A rectangular spaced mesh with a user-selectable interval was interpolated from those points and forms the basis for all future topology manipulations (Figure 1b). Creating the mesh from the 303780 DTM points collected for Mt Leyshon took about 20 seconds for Phoenix and contour lines at user selectable intervals could then be calculated and displayed in an instant (Figure 1c and 1d).
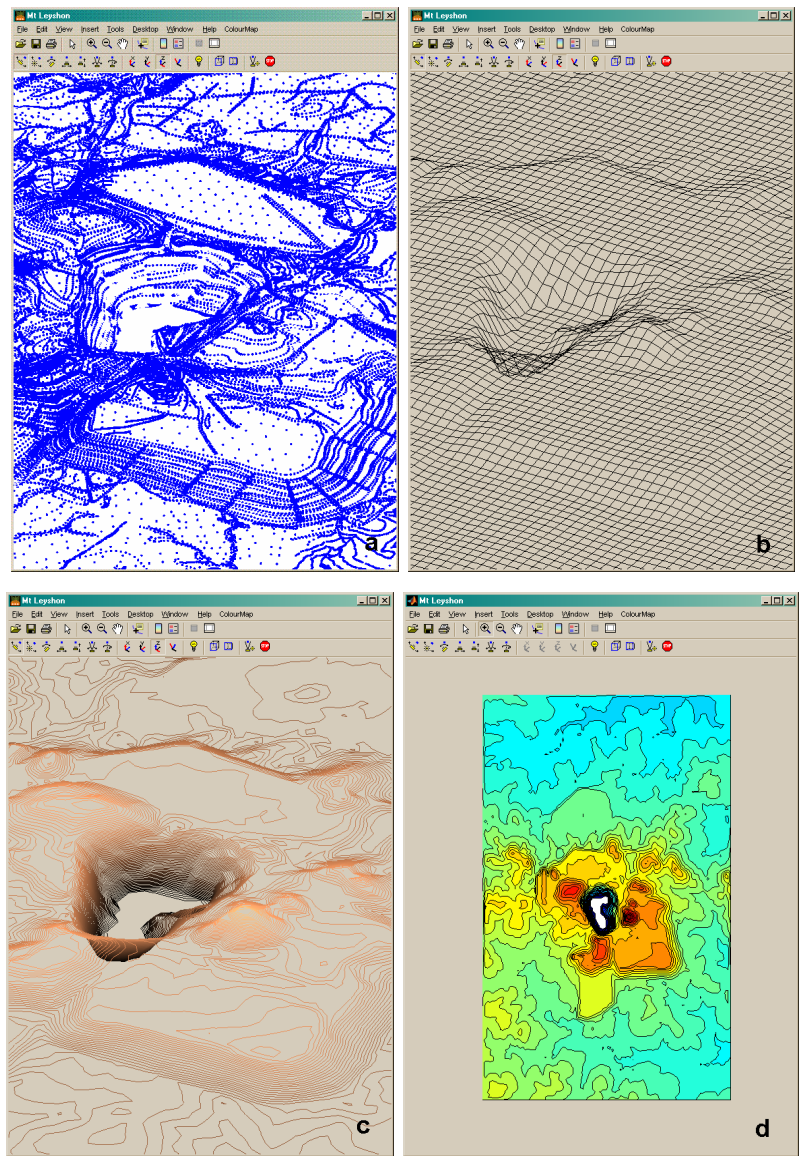

Figure 1 DTM data points digitised from aerial photos (a), the interpolated mesh at $50 \mathrm{~m}$ interval (b), variably spaced contour lines generated by Phoenix and shown in 3D (c), or colour filled (d)

\subsubsection{Sampling locations}

The position of sampling locations was determined by GPS coordinates in the field and noted using a specific marker type on the model surface in Phoenix (Figure 2). Sampling location coordinates were 
recorded in the same units of measure as had been chosen for the DTM points earlier, to avoid lengthy conversions before Phoenix data entry. Australian Map Grid coordinates (AMG84) and Cartesian units (Easting and Northing) set to metric were used for Phoenix data entry. In the case of Mt Leyshon, historic sampling location coordinates were collected in Map Grid Australia (MGA, Zone 55) and had to be converted to Australian Map Grid (AMG84, Zone 55) using a free conversion software (GeoCalc) available from http:/www.geocomp.com.au. Alternatively, when exact coordinates were not available, sampling locations were positioned manually by users with site knowledge using dominant features visible on the aerial photo.
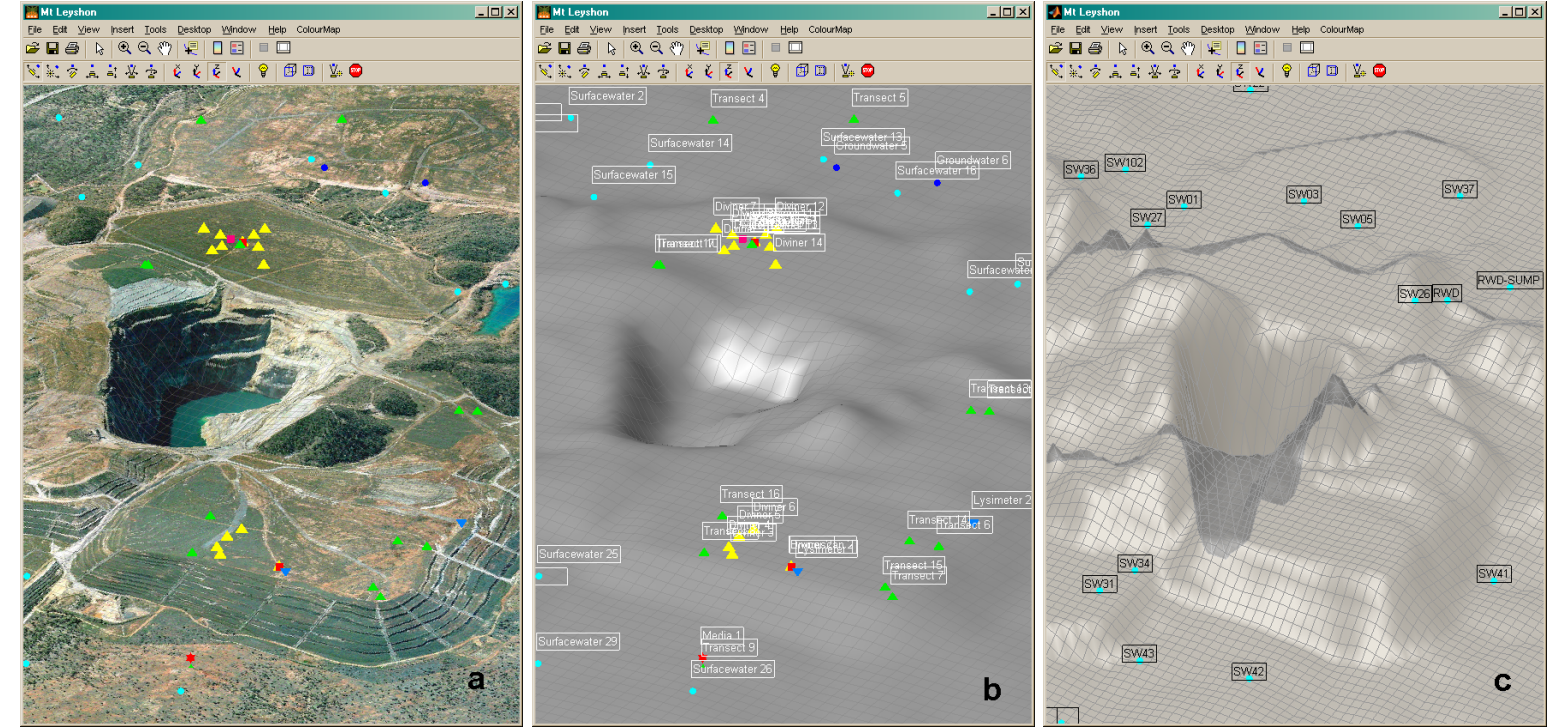

Figure 2 Phoenix model with the aerial photo draped over the surface showing various sampling locations as markers of variable shape, size and colour (a), the aerial photo replaced with a uniformly coloured surface illuminated by a light source featuring sampling locations and their labels (b), and the same surface now semi-transparent and showing the mesh and with stretched heights and selected sampling points (surface water) only (c)

\subsubsection{Sampling data}

The generic term 'sampling data' refers to site monitoring data collected via a variety of data collection methods (permanently installed loggers or once-off snapshots). This data is available in many different formats that Phoenix was designed to store and retrieve. A Phoenix sampling marker can represent a photo, a video/audio sequence, textural information and/or numeric values imported from a spreadsheet. Parameter values are imported by selecting the section of a spreadsheet that contains the sampling date/time information and the data for each parameter in a separate column. The column headings are used by Phoenix to label legends and to populate listboxes for subsequent user selection of parameters. When the user selects a sampling marker, its information is retrieved and displayed in the appropriate format, e.g. if the marker represents a video, Windows Media Player is started up playing the video clip (Figure 3a). For numeric values, the user can select the parameter(s) to graph from a list (Figure 3b). 

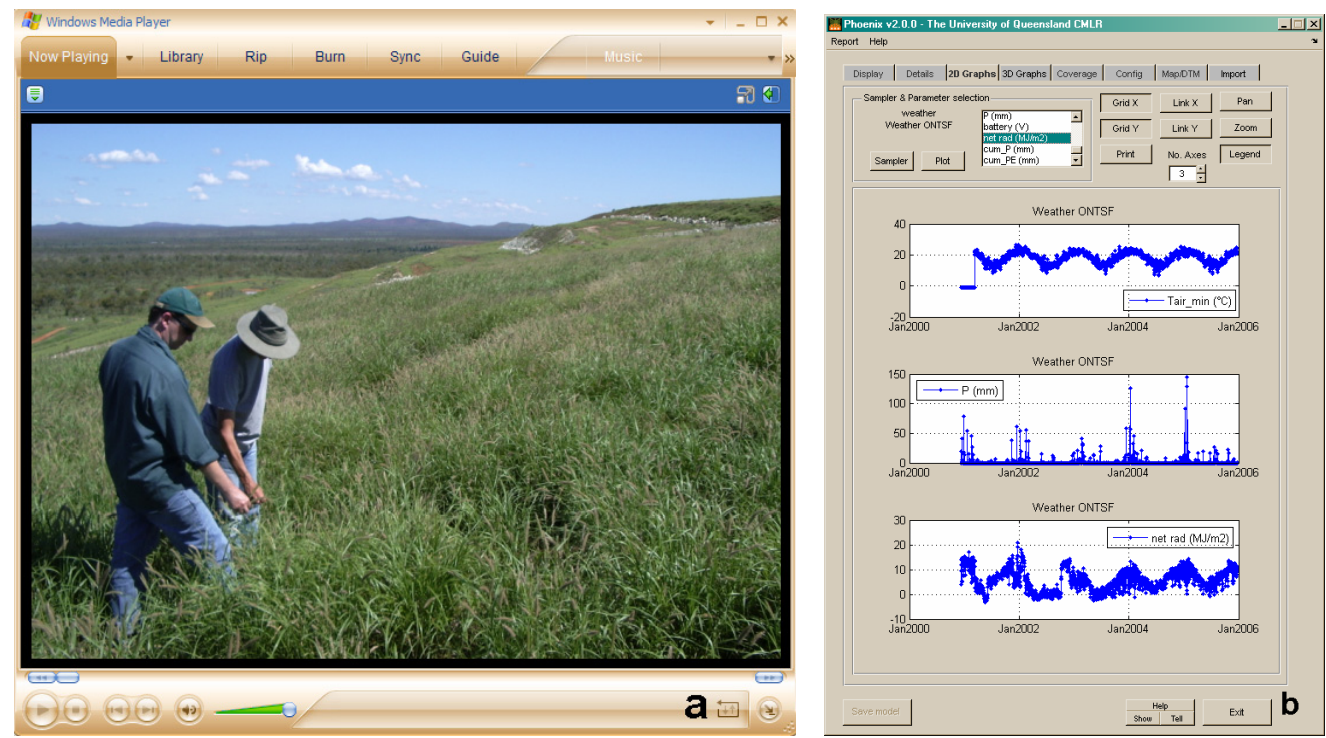

$\begin{array}{ll}\text { Figure } 3 & \text { Windows Media Player showing a short video clip with sound recording of a } \\ \text { site evaluation (a), and data collected by a weather station graphed over five } \\ \text { years (b) }\end{array}$

\section{DATA VISUALISATION AND ANALYSIS}

To facilitate data analysis, Phoenix empowers the user to visualise data captured in the model interactively using simple mouse movements. The model can be rotated, zoomed and paned in all directions by selecting buttons on the GUI control panel. The visual appearance of the model surface can also be manipulated in a variety of ways. The aerial photo (Figure 2a) can be replaced with a uniformly (user definable) coloured opaque (Figure $2 \mathrm{~b}$ ) or transparent surface, and the heights in the model can be exaggerated via a slider (Figure 2c). Sampling markers can be individually identified by type or name and displayed by type and/or date of activity.

Numeric sampling data can be analysed by plotting it in multiple windows allowing single and multiple parameters on the one graph (Figure 3b) by simply clicking the marker symbol on the map. The photo, video, site description and aerial photo available from other Phoenix windows aids the user in visualising the locality and understand the background to the data captured. If the same parameter is measured by at least three spatially distributed sampling locations, it is possible to graph it as a surface assigning the surface colour to the parameter value measured by linear interpolation between sampling locations (Figure 4). The colour bar on the right automatically reflects the overall minimum and maximum values encountered within the sampling period. Variations in parameter values over time and sampling locations can be visualised by changes in model surface colouration. Phoenix can also play an animation of these changes in surface colour over time for any user selectable time period within the data collection period of at least three sampling locations measuring identical parameters. The user can engage a synthetic voice to read out the currently displayed month and year while the surface colour animation progresses, to be able to fully focus attention on the colour changes in the different domains of concern. 

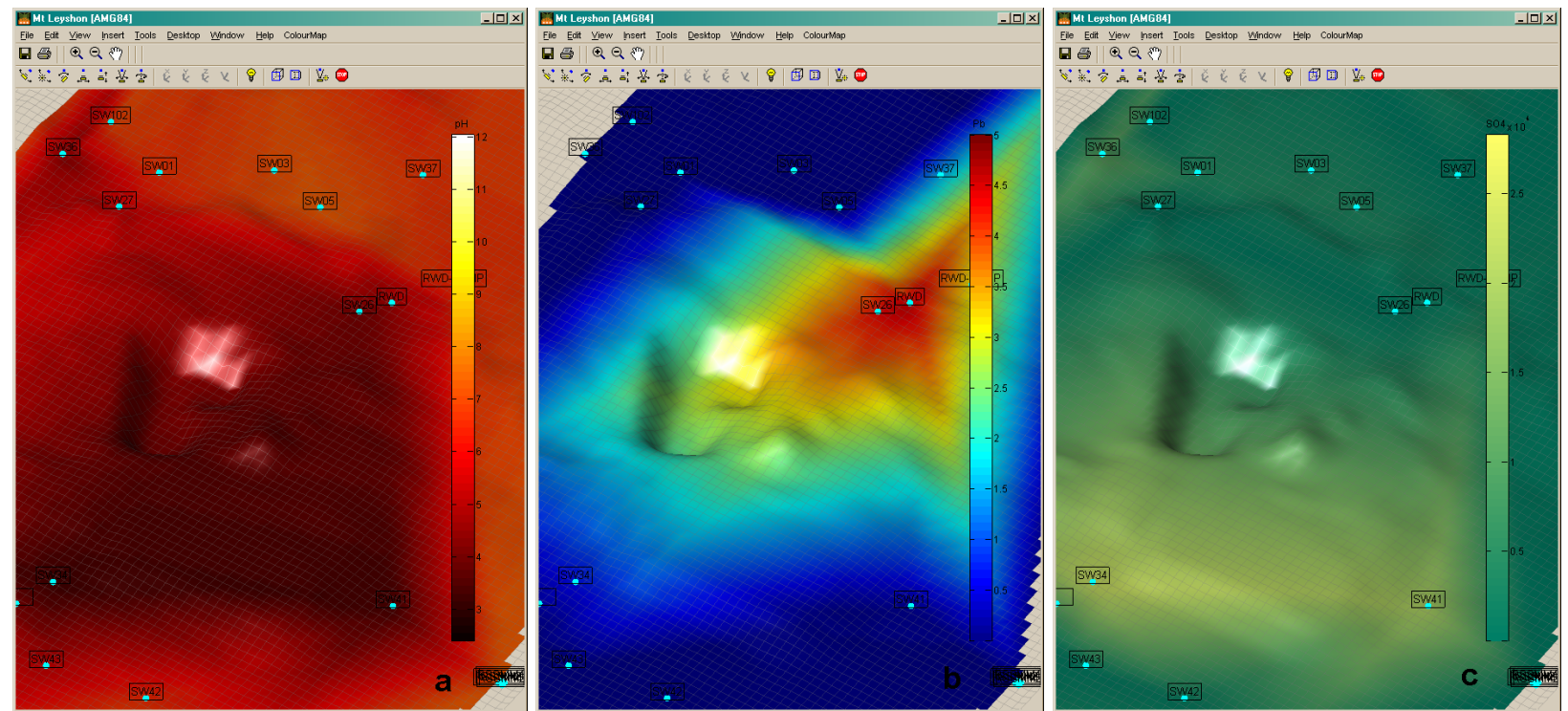

Figure 4

Parameters measured can be visualised and animated using colour gradients moving over the surface, shown here are a) $\mathrm{pH}$, b) Lead and c) $\mathrm{SO}_{4}$ in surface water at a particular point in time

To assist with the quick analysis of compliance point sampling data, Phoenix provides an option to link individual parameters to environmental authority exceedance values, trigger values or other threshold limits. An arbitrary number of both, lower and upper limits, can be linked to any single parameter of any sampling location. Lower limits can be useful for $\mathrm{pH}$ or nutrients, upper limits for any contaminant in general. A reporting option available in Phoenix lists exceedances by sampling location, date and parameter, and includes measured value, limiting value, the standard exceeded and its code. Threshold values can also be included on graphs as a horizontal line. An exceedance alert option is available as a html report viewable and printable from a web browser. The format of this and other general sampling reports can be customized by the user via Extensible Stylesheet Language (XSL) style sheets.

\section{THE ADVANTAGES OF USING PHOENIX FOR SITE CLOSURE OPERATIONS}

\subsection{Keeping a Record of Site Historic Information}

The mining industry traditionally suffers from a large turnover in its workforce (Beach et al., 2003) and every mine is closed at some point in time in the not so distant future. The impact of the associated loss of information is considerably increased at the time of mine closure when not only personnel, but also infrastructure is removed from site. Rehabilitation work however, can carry on for a long time after closure, is performed by only a few people remaining on site, and relies on the vast knowledge collected during site operations. The removal of personal computers and copying of C-Drives onto CD in an effort to backup vital information without realising that some files can only be read by proprietary software packages that require the purchase of an appropriate license is a realistic threat. With the departure of staff and filing cabinets comes not only the loss of information but also the loss of its location and how to retrieve it. Phoenix provides a solution to the data storage problem by enabling users to store different data formats side-by-side maintaining a site history record which can be retrieved, visualised and analysed by clicking on a sampling location on the model's surface.

\subsection{Site Data Quality Improvement}

The use of Phoenix by an organisation forces a certain rigor onto the users since all data has to be collected and inserted into the system first to be able to be retrieved easily with Phoenix later. This undertaking usually reveals some shortcomings in existing procedures, some of which are listed in Table 1 . The reason why those 
shortcomings can lie dormant for a long time and are only revealed when populating Phoenix with site data, lies in the fact that the physical location component was only available as text. Phoenix forces the user to convert this written information into the actual spatial location which only then makes shortcomings of the existing system visible to the eye. Furthermore, the data quality can only be assessed effectively when viewed in context with other data, so a gap or anomaly in logger data may go undetected for a while since a file is still copied from the device to a folder on the user's PC for example. Overall, the discipline resulting from the use of Phoenix gradually leads to site data quality improvement.

\section{Table $1 \quad$ Examples of hidden shortcomings rectified when employing Phoenix}

\begin{tabular}{|l|l|}
\hline Shortcomings present but hidden when: & Revealed and rectified when: \\
\hline $\begin{array}{l}\text { Aerial site photo does not exactly match DTM site } \\
\text { coordinates. }\end{array}$ & $\begin{array}{l}\text { Draping aerial photo over interpolated mesh and } \\
\text { visual inspections shows that elevations on photo } \\
\text { do not have a matching elevation in the mesh. }\end{array}$ \\
\hline $\begin{array}{l}\text { Coordinates collected/documented are recorded in } \\
\text { inappropriate or inconsistent coordinate systems. }\end{array}$ & $\begin{array}{l}\text { Site sampling location is off the edge of the site } \\
\text { map or in an absurd position according to the } \\
\text { surface model. }\end{array}$ \\
\hline $\begin{array}{l}\text { GPS coordinates for sampling location are collected } \\
\text { from the wrong location in the field. }\end{array}$ & $\begin{array}{l}\text { Sampling locations placed on aerial photo surface } \\
\text { model do not coincide with landmarks, e.g. a } \\
\text { water sampling coordinates are not anywhere near } \\
\text { the creek. }\end{array}$ \\
\hline $\begin{array}{l}\text { The sampling location changes but sampling location } \\
\text { name remains the same causing confusion. }\end{array}$ & $\begin{array}{l}\text { Cross-checking sampling coordinates in different } \\
\text { documents during sampling location entry in } \\
\text { Phoenix. }\end{array}$ \\
\hline $\begin{array}{l}\text { The same sampling location has been assigned } \\
\text { different names over time creating the misconception } \\
\text { that it is a different location. }\end{array}$ & $\begin{array}{l}\text { Entering sampling location coordinates and } \\
\text { keeping a track history of name changes over time } \\
\text { in the Phoenix site description. }\end{array}$ \\
\hline Data logger is not functioning correctly. & $\begin{array}{l}\text { Data graphed in Phoenix shows missing or absurd } \\
\text { values, e.g. weather station power supply voltage } \\
\text { fluctuates, cables chewed by cattle. }\end{array}$ \\
\hline $\begin{array}{l}\text { Data logger installation dates are wrongly } \\
\text { documented. }\end{array}$ & $\begin{array}{l}\text { Entering logger data and Phoenix reports that the } \\
\text { sampling date is earlier than the logger installation } \\
\text { date. }\end{array}$ \\
\hline $\begin{array}{l}\text { field staff follows dry water course upstream when } \\
\text { water effectively creating a new sampling location }\end{array}$ & $\begin{array}{l}\text { Spikes in parameter values caused by increase in } \\
\text { parameter concentrations in evaporating stagnant } \\
\text { pools of water. }\end{array}$ \\
\hline Laboratory data is analysed or processed wrongly. & $\begin{array}{l}\text { Aberrant pattern displayed when graphing data in } \\
\text { Phoenix. }\end{array}$ \\
\hline
\end{tabular}

\subsection{Assisting with Decision Making}

Phoenix makes the complete collection of site knowledge available to the decision makers (industry, regulating bodies and researchers alike) that are responsible for planning sustainable rehabilitation strategies for mine closure and lease relinquishment. It enables these professionals to develop a holistic view from the large volumes of diverse historic and current data, to better understand the complex interacting processes causing environmental concern, to share this information to minimise impacts to the environment and the 
community, and therefore to make informed decisions. Phoenix has been very effectively applied to the Kidston (Placer Dome / Barrick) and Mt Leyshon (Newmont) closure projects.

\section{CONCLUSION AND FUTURE SOFTWARE DEVELOPMENTS}

Phoenix provides many benefits to a mining operation, i) preservation of historic data in a single easy accessible repository protecting the company's investments into the data collection process over many generations of staff, ii) providing a one-stop-shop interface to all formats of data, iii) greatly reducing the probability of errors during data collection mainly due to the use of visual input requirements, and iv) assisting responsible parties with making informed decisions.

Current and future developments of the software will take advantage of the data stored in Phoenix to predict how the various measured components across the landscape will interact with each other in the future, thus rationalising the need and/or intensity and/or longevity of continually collecting experimental data on site. This will enable the mining industry to model the long-term effects of site rehabilitation strategies to support the development of informed sustainable rehabilitation strategies and environmental management plans.

\section{ACKNOWLEDGEMENTS}

We are grateful to Newmont Australia Ltd. for allowing us to use the data associated with the Mt Leyshon gold mine in this paper. Thank you also to Jamie Hansen (AAMHatch) who provided the aerial photography and DTM data, and the staff of CMLR, who contributed their ideas to the development of Phoenix.

\section{REFERENCES}

Beach, R., Brereton, D. and Cliff, D. (2003) Workforce Turnover in FIFO Mining Operations in Australia: An Exploratory Study, Centre for Social Responsibility in Mining, Sustainable Minerals Institute, University of Queensland.

Pudmenzky, A. (2006) Phoenix: One-Stop-Shop Mine Rehabilitation Software, The Centre for Mined Land Rehabilitation, retrieved: 7 August 2006 from http://phoenix.cmlr.uq.edu.au. 